\title{
Fabric Structure for Moisture Retention Property and Its Application in Civil Engineering
}

\author{
K. Thangamani, Prem Kumar \\ Department of Textile Technology, Kumaraguru College of Technology, Coimbatore, India \\ Email: ktmanithanga@yahoo.co.in
}

Received 10 September 2015; accepted 15 October 2015; published 22 October 2015

\begin{abstract}
The article reveals the development and analysis of fabric structure for its moisture absorbency property and its application in Civil engineering for curing of concrete. The presence of moisture in concrete and time of curing are the major influencing factors for concrete strength. Normal practice of curing is to wrap the concrete with jute woven fabric and spraying of water. The absorbency characteristics of different GSM (Gram per square meter) of woven and Non-woven fabric were studied. The Non-woven fabric absorbency is superior to woven fabric of same GSM by its three dimensional structure and high pore volume. The strength of concrete cured with Nonwoven fabric is $2.1 \mathrm{~N} / \mathrm{mm}^{2}$ higher than woven fabric of same $350 \mathrm{GSM}$. The difference in compressive strength of Non-woven fabric of $350 \mathrm{GSM}$ and $750 \mathrm{GSM}$ is $0.06 \mathrm{~N} / \mathrm{mm}^{2}$ which is marginal.
\end{abstract}

\section{Keywords}

Non-Woven, Fabric Structure, Moisture Retention, Concrete, Curing, Hydration and Compressive Strength

\section{Introduction}

With ever increasing demand for absorbent product, textiles are finding application in many areas like Medical, Industrial and so on. This flagged the way for development of new product for specific application. Textile woven jute fabric is used in Civil engineering for curing of vertical columns and slops. Curing is the process of keeping [1] the concrete moist \& warms enough for hydration. The strength of concrete depends on curing reaction \& time of curing. There should be continuous supply \& uniform distribution of moisture throughout the curing process. In absence of curing; heat generated inside the concrete cause stress \& result in crack formation. The compressive strength [2] of concrete decreases with increase in temperature, as the evaporation of water takes place at high temperature and results reduction in hydration reaction. Age of concrete also plays an important role. For the first day, concrete strength increases with temperature, as huge amount of water present in concrete. Strength of concrete [3] primarily depends upon the strength of cement paste. The strength of cement paste depends upon the dilution of paste. It is normal practice to maintain the water cement ratio of 0.4 for good hydration. In case of: 
- With water cement ratio of 0.2 , water is inadequate for hydration

- With water cement ratio of 0.4 , water available is sufficient for full hydration \& cement gel occupies all space without any air pores

- With water cement ratio of 0.6, water available is more that required quantity. Full hydration takes place \& the free water occupies in concrete evaporates creating void space. This reduces the strength of the concrete.

There are different methods of curing, one of which is wet covering (using gunny bags). The gunny bags are wrapped over the concrete and water is sprayed. The drawback with this is water evaporates quickly from gunny bag and affects the hydration process. So, if a textile structure can hold more amounts of water and transfer to concrete, the continuous curing process takes place resulting in improvement in concrete strength.

\section{Fabric Structure on Absorbency}

The structure of fabric has greater influence on absorbency and distribution. The absorbency of fabric [4] is influenced by the porous structure, consisting of fibre substance and space. The space rate of fabric is the ratio of the volume of space to the volume of a fabric. The comparative study of plain weave and twill weave shows, the intersection points in twill weave are lowers than plain weave for the unit area and threads in twill weave are free. For this reason twill weave sample are large in space rate and absorption is also large than plain weave. But when the space rate is increased beyond a limit, weak link is created between water molecules and water holding capacity decreases when fabric is positioned vertically.

The extrinsic rate of sorption (ERS) for a particular depth [5] of needle penetration of Jute Non-woven fabric increases initially with increase in punch density and then decreases. Increase in punch density means the increase in channels through the water penetrates easily and hence initially ERS increases. Further increases in punch density creates disturbance in the fibre arrangement, may be due to breakage which leads to decrease in ERS. Hygroscopic nature [6] is directly related to polarity of its polymers \& the ratio of its amorphous \& crystalline region. A hygroscopic polymer has predominantly amorphous polymer system consisting of polar groups. These attack water molecules, while the amorphous nature allows entry of the water molecule into the polymer system.

With the absence of external force [7] the transport of liquid into fibrous assembly is driven by capillary force that arises from the wetting of fibre surface. In order for wicking to take place spontaneously the balance of energy has to be such that energy is gained as the liquid advances into the material. The moisture is transmitted into the fabric in two ways, by diffusion of water vapour through the fabric and by wicking of liquid water by capillary transport. This depends on surface property of fibre, total surface area. The size and number of capillary path are also important. Wicking [8] takes place only in the wetted fabrics. The wicking depends upon the contact angle. Wicking will not take place in the man-made fibre like polyester but the transport of liquid will takes place. Wicking is the transfer of liquid water through the capillary interstices of the yarn. Wicking depends on wettability of fibre surface, as well as the structure of the yarn and fabric. In contrast to diffusion of water vapour, wicking increases as moisture regain decreases, because the fibre does not absorb the water.

\section{Experiments}

\subsection{Materials Used}

Jute materials of both woven and Non-woven with varying GSM are used. Table 1 and Table 2 give the specification of Jute fabric.

Table 1. Specification of Jute woven sample.

\begin{tabular}{|c|c|c|c|c|c|c|c|}
\hline S. no & Weave & GSM & Sample weight in gms $(10 \times 10 \mathrm{~cm})$ & Warp count $\mathrm{Nju}^{\#}$ & Weft count $\mathrm{Nju}^{\#}$ & EPI & PPI \\
\hline 1 & Plain & 350 & 3.50 & 10 & 10 & 12 & 12 \\
\hline 2 & Plain & 450 & 4.50 & 9 & 11 & 12 & 12 \\
\hline 3 & Plain & 550 & 5.50 & 10 & 12 & 12 & 14 \\
\hline 4 & Plain & 650 & 6.50 & 11 & 13 & 17 & 16 \\
\hline 5 & Plain & 750 & 7.50 & 12 & 12 & 18 & 16 \\
\hline
\end{tabular}

$\mathrm{Nju}=$ Number in jute system, EPI = Ends per inch, PPI = Picks per inch. [\#Nju, is a direct system of numbering where 14,400 yards of yarn, weighed in pounds gives the count of yarn.] 
Table 2. Specification of Jute Non-woven sample.

\begin{tabular}{cccccc}
\hline S. no & GSM & Sample weight $\mathbf{( 1 0} \times \mathbf{1 0} \mathbf{~ c m})$ & Thickness of Material $\mathbf{( m m )}$ & Type of Web laying & Type of bonding \\
\hline 1 & 350 & 3.50 & 3 & Cross laying & Needle punching \\
2 & 450 & 4.50 & 4 & Cross laying & Needle punching \\
3 & 550 & 5.50 & 5 & Cross laying & Needle punching \\
4 & 650 & 6.50 & 6 & Cross laying & Needle punching \\
5 & 750 & 7.50 & 7 & Cross laying & Needle punching \\
\hline
\end{tabular}

\subsection{Experimental Design}

Fabric of $10 \times 10$ centimetres is sprayed with $10 \mathrm{ml}$ of water for prewetting. The prewetted fabric is positioned vertically and measured water is supplied to fabric. The supply water is stopped when the first water droplet falls from the fabric. Below the fabric a beaker is placed to collect the excess water. After water droplets stops falling, the water retention capacity of fabric is calculated by

$$
A 4=A 1+A 2-A 3
$$

where

A1: Prewetting fabric, A2: Water poured on the fabric, A3: Water in beaker, A4: Water retention capacity of fabric.

The fabric is placed in a humid chamber at the predetermined temperature for drying. During drying the fabric is weighed every $15 \mathrm{~min}$ to calculate the rate of drying.

\subsection{Concrete Preparation and Testing Method}

\subsubsection{Preparation of Concrete Mould and Samples}

Concrete of size $100 \times 100 \times 100$ centimetre cube is prepared with mix proportion of 1:1.5:3 (Cement: fine aggregate: course aggregate) and water cement ratio of 0.4 for M20 concrete.

\subsubsection{Curing of Specimens}

Specimens are removed from the moulds after 24 hours and wrapped with woven and Non-woven of same GSM. The wrapped concrete is immersed in water for 10 minutes and kept in room temperature. This process is continued for 7 days and compressive strength of concrete is tested.

\subsubsection{Terminology Used}

a) Absorption capacity: It is the mass of fluid absorbed by the fabric/mass of the sample [8].

b) First crack: It is the load at which the first crack starts appearing in concrete during compressive strength testing.

c) Ultimate failure: It is the maximum load concrete can withstand during compressive strength testing.

\section{Results and Discussion}

\subsection{Water Retentivity and Drying Time of Different Fabrics}

Table 3 and Table 4 show the retentivity and drying time of different fabric. Overall the Non-woven structures have retained higher water retaining capacity compared to woven fabric of same GSM. The water retaining capacity of Non-woven fabric is increased proportionately based on the GSM of fabric [232 minutes being the highest for 750 GSM Non-woven's]. The absorption capacity is calculated on the weight of the parent material, was also consistently higher for the Nonwoven structures.

From Figure 1 it is observed that 350 GSM Non-woven fabrics at $35^{\circ} \mathrm{C}$ and $\mathrm{RH} 50 \%$ has retained water for 2.5 hours where as woven fabric retained water for 0.5 hours.

Figure 2 shows that drying time of woven fabric increased as a function of GSM. The nature of change in absorption capacity (the slope of the curves) has however been different. Higher GSM fabrics have lost water at 


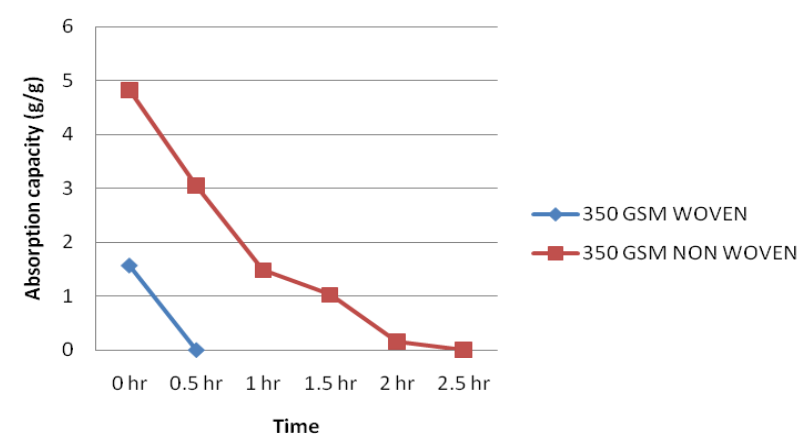

Figure 1. Drying rate of Woven and Non-woven sample of 350 GSM tested at $35^{\circ} \mathrm{C}$ and $\mathrm{RH}=50 \%$.

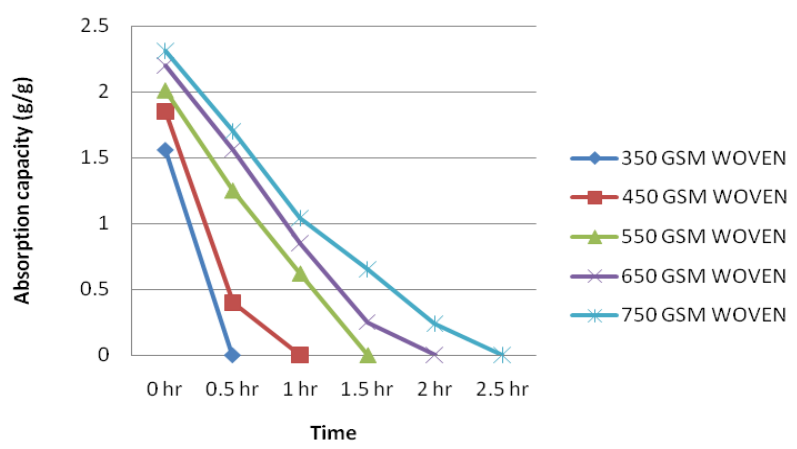

Figure 2. Drying rate of Woven sample tested at $35^{\circ} \mathrm{C}$ and $\mathrm{RH}$ $=50 \%$.

Table 3. Drying time of woven sample tested at varying condition.

\begin{tabular}{|c|c|c|c|c|c|c|}
\hline \multirow[b]{2}{*}{ S. no } & \multirow[b]{2}{*}{ GSM } & \multirow{2}{*}{$\begin{array}{l}\text { Sample weight } \\
(10 \times 10 \mathrm{~cm})(\mathrm{g})\end{array}$} & \multirow{2}{*}{$\begin{array}{c}\text { Maximum } \\
\text { water } \\
\text { holding (ml) }\end{array}$} & \multirow{2}{*}{$\begin{array}{c}\text { Maximum } \\
\text { absorption } \\
\text { capacity (\%) }\end{array}$} & \multicolumn{2}{|c|}{ Drying time in minutes } \\
\hline & & & & & $\begin{array}{c}\text { Temp } 35^{\circ} \mathrm{C} \text { and } \\
\text { RH }=50 \%\end{array}$ & $\begin{array}{c}\text { Temp } 45^{\circ} \mathrm{C} \text { and } \\
\text { RH }=70 \%\end{array}$ \\
\hline 1 & 350 & 3.50 & 10 & 156 & $32 \mathrm{~min}$ & $17 \mathrm{~min}$ \\
\hline 2 & 450 & 4.50 & 12 & 185 & $65 \mathrm{~min}$ & $20 \mathrm{~min}$ \\
\hline 3 & 550 & 5.50 & 17 & 200 & $95 \mathrm{~min}$ & $48 \mathrm{~min}$ \\
\hline 4 & 650 & 6.50 & 22 & 22 & $123 \min$ & $73 \mathrm{~min}$ \\
\hline 5 & 750 & 7.50 & 28 & 230 & $155 \min$ & $80 \mathrm{~min}$ \\
\hline
\end{tabular}

Table 4. Drying time of non-woven sample tested at varying condition.

\begin{tabular}{|c|c|c|c|c|c|c|}
\hline \multirow[b]{2}{*}{ S. No } & \multirow[b]{2}{*}{ GSM } & \multirow{2}{*}{$\begin{array}{l}\text { Sample weight } \\
(10 \times 10 \mathrm{~cm})(\mathrm{g})\end{array}$} & \multirow{2}{*}{$\begin{array}{c}\text { Maximum water } \\
\text { holding } \\
\text { capacity (ml) }\end{array}$} & \multirow{2}{*}{$\begin{array}{c}\text { Maximum } \\
\text { absorption } \\
\text { capacity (\%) }\end{array}$} & \multicolumn{2}{|c|}{ Drying time in minutes } \\
\hline & & & & & $\begin{array}{c}\text { Temp } 35^{\circ} \mathrm{C} \text { and } \\
\text { RH }=50 \%\end{array}$ & $\begin{array}{c}\text { Temp } 45^{\circ} \mathrm{C} \text { and } \\
\mathrm{RH}=70 \%\end{array}$ \\
\hline 1 & 350 & 3.50 & 20 & 483 & $150 \mathrm{~min}$ & $90 \mathrm{~min}$ \\
\hline 2 & 450 & 4.50 & 25 & 490 & $160 \mathrm{~min}$ & $120 \mathrm{~min}$ \\
\hline 3 & 550 & 5.50 & 30 & 340 & 176 min & $145 \min$ \\
\hline 4 & 650 & 6.50 & 35 & 360 & $212 \min$ & 163 min \\
\hline 5 & 750 & 7.50 & 40 & 360 & $232 \min$ & 192 min \\
\hline
\end{tabular}


a slower rate. The 750 GSM woven fabric retained water for 2.5 hours which is improvement of 2 hours over the lower350 GSM material.

From Figure 3 it is observed that time of drying for 750 GSM is 3.8 hrs and reduces with reduction in fabric GSM. It is interesting to note that for Non-woven structures, the initial absorption capacity is higher for lower GSM fabric as evident for 3570 GSM and 450 GSM fabric. This happens as a light structure immediately absorb more water but simultaneously looses water at a higher rate which is seen from the higher slope of the curve. On the contrary, a more dense nonwoven structure doesn't allow initial water to get through fast but water absorbed is trapped in the more intense structure and retained for long.

\subsection{Strength of Concrete}

Table 5 gives the compressive strength of concrete. The Non-woven wrapped concrete samples were found to have higher strength and bear heavy load before the appearance of first crack. The Non-woven fabric wrapped concrete has compressive strength of $2.1 \mathrm{~N} / \mathrm{mm}^{2}$ higher than woven of same $350 \mathrm{GSM}$. Concrete cured without fabric (NF) has an average compressive strength $1.3 \mathrm{~N} / \mathrm{mm}^{2}$ and $3.4 \mathrm{~N} / \mathrm{mm}^{2}$ lower than concrete cured with both woven and Non-woven fabric of 350 GSM. Concrete cured with Non-woven fabric of 750 GSM has small increase in average compressive strength of $0.06 \mathrm{~N} / \mathrm{mm}^{2}$ compared with 350 GSM of Non-woven fabrics.

\section{Conclusion}

Non-woven materials were found to be overall better in terms of retention of water tested under varying conditions of temperature and RH. Non-woven fabric has on an average retained $20 \%$ more water when compared to

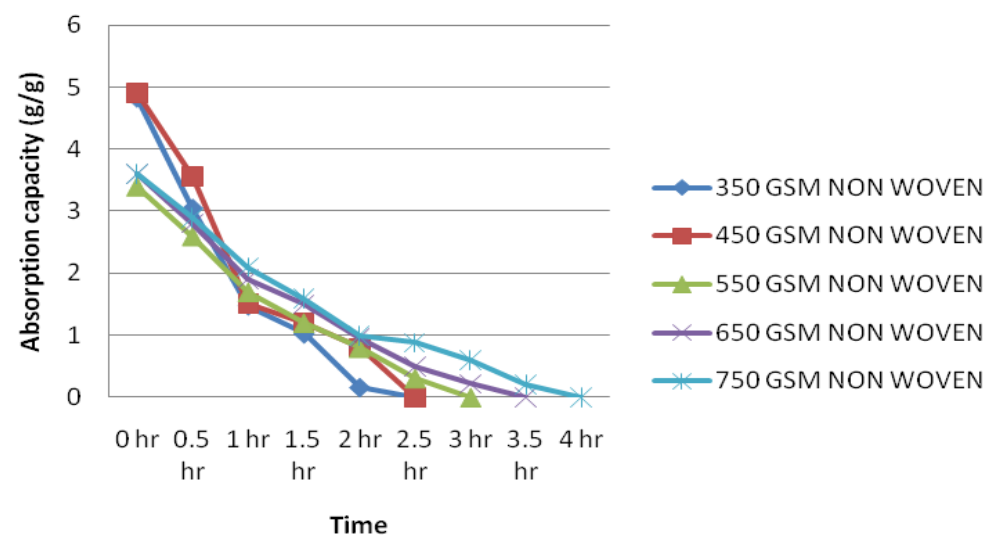

Figure 3. Drying rate of non-woven sample tested at $35^{\circ} \mathrm{C}$ and $\mathrm{RH}=50 \%$.

Table 5. Compressive strength of concrete cured with different fabrics for 7 days.

\begin{tabular}{ccc}
\hline \multirow{2}{*}{ Fabric specification } & \multicolumn{2}{c}{ Compressive strength (N/mm $\mathbf{m}^{2}$} \\
\cline { 2 - 3 } NF & First Crack & Ultimate Crack \\
\hline WF 350 GSM & 8.55 & 16.10 \\
NWF 350 GSM & 13.3 & 17.40 \\
NWF 450 GSM & 18.4 & 19.50 \\
NWF 550 GSM & 18.4 & 19.51 \\
NWF 650 GSM & 18.5 & 19.53 \\
NWF 750 GSM & 18.6 & 19.55 \\
\hline
\end{tabular}

NF-No fabric, WF-Woven Fabric, NWF-Non-Woven Fabric. 
their similar GSM woven counterpart. The higher retention of water by nonwovens has been used to cure concrete and a comparison made with concrete cured with similar GSM woven fabric. Concrete samples cured with Non-woven materials had at least $20 \%$ higher compressive strength when compared to woven fabrics of same GSM. This can be ascribed as a direct result of higher water retention of Non-woven structures.

\section{References}

[1] Neville, A.M. (1997) Properties of Concrete. 325.

[2] Kulkarni, P.D., Ghose, R.K. and Phull, Y.R. (1998) Text Book of Concrete Technology. 31.

[3] Shetty, M.S. (2001) Concrete Technology. 283.

[4] Sawazaki, K. (1964) Water Absorbency of Fabrics. Fukui University, Fukui, 232.

[5] Sengupta, S. (2009) Water Absorbency of Jute Needle-Punched Nonwoven Fabric. IJFTR, 349.

[6] Ghol, E.P.G. and Vilensky, L.D. (1987) Textile Science. 39.

[7] Saville, P.B. (1999) Physical Testing of Textiles. Textile Institute, 226.

[8] Ramachamdran, T. and Kesavaraja, N. (2004) A Study on Influencing Factors for Wetting \& Wicking Behaviour IE (I). Journal 184. 